\title{
Neuroanatomia das cores
}

\author{
Dr. Fabiano de Abreu Agrela Rodrigues ${ }^{1}$ \\ deabreu.fabiano@gmail.com
}

\section{RESUMO}

A incidência de luz em determinados objetos emite diferentes freqüências e tamanhos de ondas eletromagnéticas que ao serem captadas pela retina, enviam um sinal para o córtex visual que organiza a imagem e gera uma determinada coloração, sendo assim a percepção da cor é uma interação entre ondas, olhos e cérebro. O presente artigo tem como objetivo uma revisão literária sobre o processo de captação de luz até a percepção da cor no cérebro e discorrer sobre como determinadas cores podem influenciar comportamentos.

Palavras-chaves: cores; neurociência; comportamento; cérebro.

\footnotetext{
${ }^{1} \mathrm{PhD}$, neurocientista, mestre em psicanálise, biólogo, historiador, antropólogo, com formações também em neuropsicologia, neurolinguística, neuroplasticidade, inteligência artificial, neurociência aplicada à aprendizagem, filosofia, jornalismo, programação em python e formação profissional em nutrição clínica Diretor do Centro de Pesquisas e Análises Heráclito; Chefe do Departamento de Ciências e Tecnologia da Logos University International e da City University; Membro da SFN - Society for Neuroscience, Membro Redilat.
} 


\title{
Color neuroanatomy
}

\begin{abstract}
The incidence of light on certain objects emits different frequencies and sizes of electromagnetic waves that, when captured by the retina, send a signal to the visual cortex that organizes the image and generates a certain coloration. This article aims to review the literature on the process of light capture to the perception of color in the brain and discuss how certain colors can influence behavior.
\end{abstract}

Keywords: colors; neuroscience; behavior; brain.

Artículo recibido: 02 enero 2022 Aceptado para publicación: 28 enero 2022 Correspondencia: deabreu.fabiano@gmail.com Conflictos de Interés: Ninguna que declarar 


\section{INTRODUÇÃO}

Quando as luzes são emitidas e refletidas em um objeto, elas geram ondas eletromagnéticas que são captadas pelas retinas e decifradas pelo sistema nervoso, especificamente as áreas visuais do cérebro. As noções do que é uma cor mudam pois elas se transformam constantemente.

Em primeiro lugar, existem comprimentos de ondas eletromagnéticas que não são percebida a olho e, portanto, há tonalidades de cores que o ser humano não pode ver, muitos animais vêem menos cores, outros percebem mais. Outra influência são as combinações de cores que se transformam em outras cores, a cor de fundo, a quantidade de luz no ambiente, o ângulo em que essas cores são vistas e etc.

Muitos cientistas como Isaac Newton, Goethe, da Vinci buscaram entender o processo de formação das cores, fazendo varias testes com as cores ES freqüências de ondas, experimentos com luz e a natureza das cores. Goethe também pesquisou sobre os fatores psicológicos que as cores causam. Todos eles foram responsáveis pela ampliação de um estudo chamado a teoria das cores.

As cores estão ligadas a um fator estético, na natureza existe uma harmonização entre as suas variadas junções. Harmonia triádica, monocromática, análoga e complementar (CIOTTI, 2014).

Quanto às tonalidades, as cores se dividem em primárias, secundarias e terciárias. Essa divisão é feita quanto à pureza do tom, as cores primárias - vermelhas azuis e amarelas não podem ser criadas pelas misturas de outras. É com as variadas misturas dessas cores fundamentais que se formam todas as outras. As secundarias são formadas com a mistura de partes iguais com duas cores primárias e as terciárias são criadas com a mistura de uma secundária e uma primária.

Hoje em dia, as cores são amplamente estudadas nas áreas de marketing para a construção da personalidade de uma marca e a forma com que ela irá se comunicar com o seu público alvo. Elas são consideradas aliadas no processo de persuasão para o consumo de um determinado serviço ou compra de um produto.

Elas também estão ligadas a forma com que as pessoas se vestem, caracterizando melhor suas personalidades e a forma com que se apresentam para o mundo, além de ambientes diversos como os internos, arquitetura, arte, símbolos que geram comportamentos e estão presentes em redes sociais, tecnologia, ambientes urbanos etc. 


\section{NEUROANATOMIA DAS CORES}

As cores e a forma como são percebidas estão relacionadas com a luz e suas ondas eletromagnéticas que refletem nos objetos e chegam aos nossos olhos. As ondas de luz se propagam em diferentes velocidades e essa diferença é a responsável por produzir as diferentes cores que os humanos podem perceber.

De acordo com Rocha (2010) as cores são percebidas pela retina que cobre a parte de trás do globo ocular e possui dois tipos de fotorreceptores de luz: os cones que percebem as cores azul, vermelho e verde e os bastonetes que percebem os tons de cinza. As ondas eletromagnéticas da luz se diferenciam entre baixa frequiência e alta freqüência, e essa oscilação entre as freqüências provocada pelo tamanho da onda e oscilação dos elétrons permite a captação das diferentes cores que existem no espectro visível, tendo as cores verde, vermelho e azul como base.

Para Silva (2018) receptores dos cones na retina recebem a informação das cores pela luz. Se a cor em questão é verde, os receptores verdes serão acionados. Por causa da mudança de freqüência nas ondas de luz, mais de um receptor será acionado. Dependendo da velocidade da frequiência, ela pode acionar receptores diferentes, os que percebem a cor verde e outros que recebem a cor vermelha. Assim, com essa união entre o verde e vermelho, a informação que chegará para o cérebro é o da cor laranja.

O próprio cérebro faz esse "cálculo" dependendo da freqüência e tamanho das ondas de luz. Após esse cálculo a informação cromática do ambiente passa pelo nervo óptico e depois para o córtex visual que tem a função de organizar no cérebro de acordo com as informações que chegaram à retina. Várias partes do cérebro já foram relacionadas com a capacidade de perceber e categorizar cores: córtex visual, áreas relacionadas à linguagem, ou as áreas frontais do cérebro (SUN et al, 2021). Assim como, regiões inferiores temporais, frontais e parahipocampais.

Bramão et al (2010) afirma que objetos coloridos foram ao longo da história nomeados mais rapidamente do que objetos em preto e branco. As cores ativam a rede semântica, ou seja, criam um mapa mental e interconexão de conceitos que permite unir estes a uma cor específica. A cor tem papel fundamental no reconhecimento de objetos facilitando a recuperação do seu conceito.

Entender a ligação entre cor e linguagem é importante para responder uma das perguntas das ciências cognitivas: seriam as cores percebidas pelo olho humano e categorizadas em 
pequenos grupos "amarelo", "verde", "vermelho" reais? Ou seriam apenas construções da linguagem criadas apenas no intuito de organizar semanticamente aquela coloração específica que está sendo percebida? O que se sabe é que há uma quantidade considerável de tons que não são capazes de serem captados pelos sensores dos olhos devido à oscilação da frequiência das ondas magnéticas. Portanto, seria a cor percebida a cor real ou a cor percebida é influenciada pelo nome que foi dado a ela?

Ainda não foram encontradas alterações marcantes em áreas do cérebro sob a influência da categorização das cores, porém muitos estudos mostram que ativações sutis em áreas do cérebro ocorrem durante a percepção das tonalidades de certas tonalidades. Dois exemplos são as alterações neurais relacionadas a captação de ondas dos cones da retina que diferem entre vermelho e verde e as alterações neurais que ocorrem quando o cérebro identifica cores quentes (amarelo, laranja e vermelho) e frias (violeta, azul). Ainda assim, esses achados não são suficientes para afirmar que a linguagem molda a percepção de cor e vice - versa (BIRD et al, 2014).

Estudar a fundo sobre as cores e seus efeitos requer uma pesquisa interdisciplinar entre emoções, ciências cognitivas e percepção. É um campo extremamente abrangente onde ainda é possível perceber uma insuficiência de dados em relação a quantidade de tonalidades percebidas e não percebidas pelo olho humano, as propriedades das cores, sendo elas naturais e artificiais e as possíveis influências comportamentais que determinadas cores parecem sobrevir em indivíduos. Tais comportamentos se mostram dependentes de certos contextos para que as cores tenham sua influência: cultura, gênero, idade, tipo de serviço que está sendo oferecido e em que tipo de ambiente essa cor se apresenta.

A atuação das cores no comportamento humano e na forma como os indivíduos pensam também se relaciona com as três maiores propriedades da cor: matiz, que se refere às tonalidades da cor (amarelo, verde, vermelho); o tom, que separa as cores entre claras e escuras e depende da quantidade de luz que está sobre a cor; e a intensidade, que separa as cores entre fortes e opacas e também depende da luz.

Por conseguinte, é possível perceber que a influência da cor está presente no dia a dia das pessoas de maneira inconsciente dependendo da maneira em que ela se apresenta no ambiente. Essa influência se estende por várias áreas como atenção seletiva, desempenho intelectual e atlético, publicidade e marketing de diferentes empresas focadas em roupa, 
alimento, bebida etc., agressividade, motivação e até atração física (vestimenta) (ELLIOT, 2015).

\section{AS CORES E SEUS EFEITOS}

Psicologicamente, as cores provocam estímulos emocionais amplamente estudados pela publicidade e pelo marketing em diferentes áreas com a intenção de entregar um produto que provoque algum tipo de reação, mude seu comportamento e passe a querer consumir aquele produto. Tendo as cores grandes poderes de comunicação, estética e harmonização, elas têm grande influência no planejamento, desenvolvimento e promoção de produtos gráficos voltados para a propaganda de produtos diversos. Além disso, elas participam de tratamentos alternativos de relaxamento como a cromoterapia que procura regular a energia do corpo, por exemplo.

De acordo com Labrecque e Milne (2012) a utilização de cores por marcas e empresas pode influenciar na personalidade da marca, indicar a seu público alvo, ampliar as vendas de produtos específicos, alterar a personalidade de uma marca caso esta esteja passando por um processo de reinvenção, criar uma sensação de familiaridade, intimidade com a marca.

Para Khattak (2018), leva apenas noventa segundos para as pessoas terem opiniões sobre produtos e isso é, na maioria dos casos, influenciado pela cor apenas que provocam reações nos sentidos e no humor.

A área financeira, por exemplo, tem utilizado cores como estímulos quando se trata de investimentos. Compras de ações são influenciadas pela cor vermelha, caso a compra de determinadas ações apresentam um risco e esse risco é apresentado ao investidor com a cor vermelha, as chances aumentam do indivíduo desistir da compra (BAZLEY et al, 2017).

Ao pesquisar como as variadas cores em um campus universitário, desde prédios até espaços internos afetam a vida dos estudantes, Kurt e Osueke (2014) mostraram que as tonalidades dispostas no ambiente mudam a sua influência dependendo do contexto. $\mathrm{O}$ azul, por exemplo, demonstra mais tranqüilidade e passividade em espaços internos, mas quando está inserindo em um contexto de maior espiritualidade e imaterialidade ele se torna mais forte e ativo estando mais próximo do transcendental.

Em se tratando de cultura, as cores também mudam de significação, em algumas culturas o branco é a cor da pureza para outras simboliza tristeza e luto. Porém, é importante 
diferenciar simbolismo das cores da psicologia das cores. A psicologia das cores se refere aos estímulos sensoriais que as cores provocam independente dos aspectos culturais, de gênero e demográficos. E as cores que provocariam esses estímulos de maneira mais generalizada são azul, amarelo, verde e vermelho (KURT e OSUEKE, 2014; WRIGHT, 1995).

\subsection{Vermelho}

A cor vermelha possui uma freqüência de onda mais longa, sendo assim se apresenta como uma cor forte, e é a primeira a ser percebida pelo olho, por essa razão ela chama mais a atenção no ambiente. Está associada a força, determinação, amor, paixão, raiva, poder, perigo, calor, energia, dominância. Ela também provoca efeitos físicos como aumento dos batimentos cardíacos e aumento do metabolismo, ela provoca fome. Por essa razão que a cor vermelha é utilizada na publicidade para a venda de comida, sendo muito comum em restaurantes e fast food (AL-AYASH et al, 2016).

A cor vermelha arremete a questões emocionais com maior intensidade justamente pela frequência de onda mais longa, exigindo um maior potencial de ação sináptico.

\subsection{Verde}

Está associado à tranqüilidade, natureza, harmonia, equilíbrio, mas também com a inveja. Em pesquisas feitas com plantas foram observadas que as que possuem coloração verde produzem atitudes mais positivas e ativam as áreas do cérebro relacionadas a concentração, criatividade e atenção enquanto as flores amarelas ativavam as áreas parietais e occipitais e produziam maior sensação de felicidade (JANG et al, 2014).

\subsection{Amarelo}

A cor amarela está ligada a atenção, felicidade, empolgação, jovialidade, amizade, energia, auto-estima e criatividade, esperança, otimismo (KELLY, 2019).

\subsection{Azul}

Está relacionado com o intelecto, razão. É a cor da tranqüilidade, calma e concentração, serenidade, segurança, produtividade, disciplina e responsabilidade. Pelo outro lado, pode provocar sensações de solidão e melancolia dependendo da forma como é utilizada (KELLY, 2019).

\section{TERAPIA DAS CORES}

A utilização de cores para o tratamento de doenças físicas e cognitivas ganhou o nome de cromoterapia. Com a indicação de um profissional dessa prática pertencente à medicina 
integrativo-alternativa, o paciente é colocado em uma sala, onde recebe a emissão de ondas eletromagnéticas que atuam no equilíbrio da mente e do corpo. Luzes de diferentes cores atuam de diferentes maneiras, cores quentes estimulam enquanto as cores frias acalmam, e ajudam no tratamento complementar de diversos transtornos como na diminuição do cansaço mental, sintomas de depressão, atua no sistema nervoso, transtorno do sono e até pressão alta (AZEEMI e RAZA, 2005).

\section{CONSIDERAÇÕES FINAIS}

As cores são parte da vida das pessoas, elas estão conectadas com a estética em filmes e pinturas, são naturais e podem ser criadas, elas estão em toda parte. Elas se apresentam na presença de luz, da sua frequiência e oscilação e vão para as retinas e o córtex visual nos indica qual cor estamos vendo. As cores no nosso dia a dia apresentam diferentes influências inconscientes na forma como nos comportamos e despertam uma quantidade de sensações e emoções que nos fazem agir de determinadas maneiras.

A forma como as cores são percebidas estão relacionadas com a luz e suas ondas eletromagnéticas que refletem nos objetos e chegam aos nossos olhos. As ondas de luz se propagam em diferentes velocidades e essa diferença é a responsável por produzir as diferentes cores que os humanos podem perceber. As cores são percebidas pela retina que cobre a parte de trás do globo ocular e possui dois tipos de fotorreceptores de luz: os cones que percebem as cores azul, vermelho e verde e os bastonetes que percebem os tons de cinza. As ondas eletromagnéticas da luz se diferenciam entre baixa freqüência e alta freqüência provocada pelo tamanho da onda e oscilação dos elétrons que permite a captação das diferentes cores que existem no espectro visível, tendo as cores verde, vermelho e azul como base.

Receptores dos cones na retina recebem a informação das cores pela luz interpretando a cor. De acordo com a mudança de freqüência nas ondas de luz, mais de um receptor será acionado e dependendo da velocidade da freqüência, ela pode acionar receptores diferentes e união das cores formam outras cores.

Tonalidades de cores são absorvidas de formas diferentes de acordo com o individuo, sem grandes variações e a forma que a cor é vista, mesmo distinta por alguns, não confere regiões cerebrais nem personalidade já que nuances interferem na interpretação entre elas o ambiente por quem vê. 


\section{REFERÊNCIAS}

AL-Ayash, A., Kane, R. T., Smith, D., \& Green-Armytage, P. (2016). The influence of color on student emotion, heart rate, and performance in learning environments. Color Research \& Application, 41(2), 196-205. https://doi.org/10.1002/col.21949

Azeemi, S. T. Y., \& Raza, M. (2005). A critical analysis of chromotherapy and its scientific evolution. Evidence-based complementary and alternative medicine, 2(4), 481-488. https://doi.org/10.1093/ecam/neh137

Bazley, W. J., Cronqvist, H., \& Mormann, M. M. (2017). In the red: The effects of color on investment behavior. Swedish House of Finance research paper, 17, 16.

Bird, C. M., Berens, S. C., Horner, A. J., \& Franklin, A. (2014). Categorical encoding of color in the brain. Proceedings of the National Academy of Sciences, 111(12), 4590-4595. https://doi.org/10.1073/pnas.1315275111

Bramão, I., Faísca, L., Forkstam, C., Reis, A., \& Petersson, K. M. (2010). Cortical brain regions associated with color processing: an FMRI study. The open neuroimaging journal, 4, 164-173. https://doi.org/10.2174/1874440001004010164

Ciotti G. Color Psychology: How Colors Influence the Mind. Psychology Today. 2014;20. https://www.helpscout.com/blog/psychology-of-color/

Elliot, A. J. (2015). Color and psychological functioning: a review of theoretical and empirical in work. Frontiers psychology, 6, 368. https://doi.org/10.3389/fpsyg.2015.00368

Jang, H. S., Kim, J., Kim, K. S., \& Pak, C. H. (2014). Human brain activity and emotional responses to plant color stimuli. Color Research \& Application, 39(3), 307-316. https://doi.org/10.1002/col.21788

Khattak, D. S. R., Ali, H. A. I. D. E. R., Khan, Y. A. S. I. R., \& Shah, M. U. K. H. A. R. I. F. (2018). Color Psychology in Marketing. Journal of Business and Tourism, 4(01), 183-190.

Kelly, D. (2019). The Psychology of Color - Blue. David Kelly. https://medium.com/@davidkellyuph/the-psychology-of-color-blue5 da101e1306c 
Kelly, D. (2019). The Psychology of the Color - Yellow. David Kelly. https://medium.com/@ davidkellyuph/the-psychology-of-color-yellowfc9420cf2ff7

Kurt, S., \& Osueke, K. K. (2014). The effects of color on the moods of college students. SAGE Open, 4(1),

2158244014525423. https://doi.org/10.1177/2158244014525423

Labrecque, L.I., Milne, G.R. Exciting red and competent blue: the importance of color in marketing. J. of the Acad. Mark. Sci.40,711-727 (2012). https://doi.org/10.1007/s11747-010-0245-y

ROCHA, J. C. (2010). Cor luz, cor pigmento e os sistemas RGB e CMY. Revista Belas Artes, 3(2), 107-128.

Silva, F. (2018). O estudo do comportamento humano através do cérebro, focado na cognição cromática. Convergências-Revista de Investigação e Ensino das Artes, VOL XI (21). http://convergencias.esart.ipcb.pt/?p=article\&id=308

Wright A. The beginner's guide to colour psychology. Kyle Cathie Limited; 1995. 